\title{
Design and analysis of dual band implantable DGS antenna for medical applications
}

\author{
B PRUDHVI NADH, B T P MADHAV*® and M SIVA KUMAR
}

Department of Electronics and Communication Engineering, Antennas and Liquid Crystals Research Centre, Koneru Lakshmaiah Education Foundation, Guntur, India

e-mail: prudhvibadugu@kluniversity.in; btpmadhav@kluniversity.in; siva4580@kluniversity.in

MS received 6 February 2018; revised 12 January 2019; accepted 11 February 2019; published online 3 May 2019

\begin{abstract}
An implantable antenna is designed for body area network, industrial scientific and medical applications with low specific absorption rate (SAR). The proposed antenna with defected ground structure (DGS) is designed on the FR4 substrate as well as on polyimide substrate. The designed antenna providing dual band characteristics at (Industrial scientific and medical) ISM band of $2.5 \mathrm{GHz}$ and location application for emergency services (LAES) band at $4.2 \mathrm{GHz}$. The electromagnetic radiation is evaluated using the specific absorption rate in three layered phantom models and the SAR values of the antenna are evaluated by placing the antenna at different levels. The antenna distance is varied inside the skin layer to $5 \mathrm{~mm}$ away from the threelayered model and observed the reduction in SAR, when moving away from skin tissue. The observed value of SAR satisfies the IEEE-C95-1-2005 standards at ISM operating band. The proposed antenna is tested on threelayered phantom model in simulation through HFSS and in the real time on artificial layers with the help of combinational analyzer (CNA) connection.
\end{abstract}

Keywords. Body area network (BAN); defected ground structure (DGS); dual band; implantable antenna; medical applications; specific absorption rate (SAR).

\section{Introduction}

Wireless technology is growing rapidly in the medical communication field with applications like WBAN (wireless body area network), implantable devices communication and biomedical IOT devices, etc. In WBAN $[1,2]$ technology the electronic devices will be placed on the human body and monitoring devices will be placed outside to extract the parameters. The applications of the WBAN $[3,4]$ technology include placement of body monitoring sensors and other fitness monitoring devices with biomedical equipment. In the medical field, wireless telemetric links transmit the diagnostic, therapy and vital information to outside the body [5-7]. For transmitting the data there should be interaction between the human body and microwave fields. These issues made the researchers to pay attention and to study the radiation effects on the human body [8]. In this process the study of SAR (specific absorption rate) will measure the electromagnetic power density and radiating device effect observed by the human body [9].

However, placement of antenna on the human body leads some of the restrictions such as antenna size, safety issues, biocompatibility, propagation losses inside the body and

*For correspondence confinement of communication link [10]. So, to maintain the communication link the implantable device related with the wearable device for which on body repeater is required [11]. To study the behavior of implantable devices, human body phantoms will be used in simulation [12]. Some of the recent technologies like planar inverted-F antenna or spiral antenna are used to operate at ISM bands [13]. Dual band implantable antenna has also been studied [14] which are designed to operate at MICS band. A planar dipole antenna is designed to operate at medical device radio communication services reported in [15]. A low-profile uniplanar antenna is proposed for real time video streaming and body signal transmission applications for telemetry applications in [16-18]. Several technologies like ferrite loading, artificial magnetic conductors and electromagnetic band gap are used to reduce the effects of SAR on body reported in [19-22].

In this article compact implantable antenna is designed for ISM band. The antenna was designed to operate at dual band. When the antenna is placed $2 \mathrm{~mm}$ below the skin phantom, the antenna will cover the ISM band. The proposed antenna configuration was performed on FEM based Ansys HFSS and the simulations are performed to ensure the antenna working properly at different environments. The sensitivity of the antenna depending on the dielectric constant of the skin tissue is also analyzed in this work. To 
get the SAR parameter, antenna is placed at different heights and studied the radiation effects.

\section{Antenna design parameter}

The structure of the proposed antenna is shown in the figure 1. It is fabricated on the FR4 and polyimide dielectric substrates of dielectric constant 4.4, 3.5 with loss tangent $0.02,0.008$, respectively. The overall size of the antenna is around $58 \times 40 \times 0.8 \mathrm{~mm}$. The antenna consists of the microstrip transmission line with $50 \mathrm{ohm}$ impedance. The microstrip line is connected to symmetrical radiating elements and one of the elements is connected to metallic strip of dimension $0.5 \times 0.9 \mathrm{~mm}$ and two parasitic elements are loaded parallel to the patch elements. In the bottom structure, the antenna consists of the inverted $\mathrm{T}$-shaped ground plane. In the ground plane, a triangular slot is made with size of $4.5 \mathrm{~mm}$.

\section{Results and discussion}

The simulated reflection coefficients of the antenna model 1 to the proposed antenna model are presented in figure 2 . The antenna 1 has two symmetrical radiators in which patch are connected to the transmission line and symmetrical radiator is left free in the ground side of DGS structure. The S11 of the antenna is operating at $4.1 \mathrm{GHz}-$ $4.3 \mathrm{GHz}$ with bandwidth of $0.2 \mathrm{GHz}$. In the antenna 2 the ground plane is modified with semi-circle and rectangular strip, which looks like an inverted T- shaped ground plane. The triangular slot is made in the inverted T-shaped ground plane and with this modification, the antenna

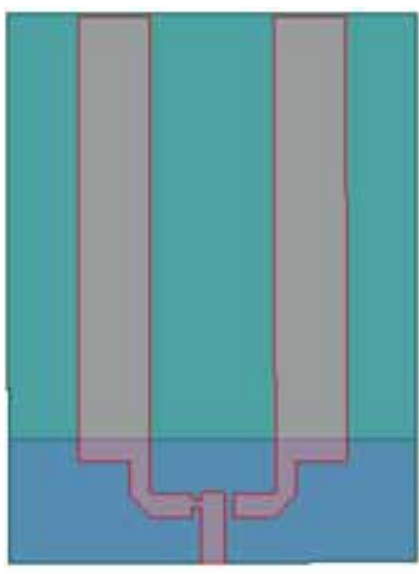

(a) Antenna 1

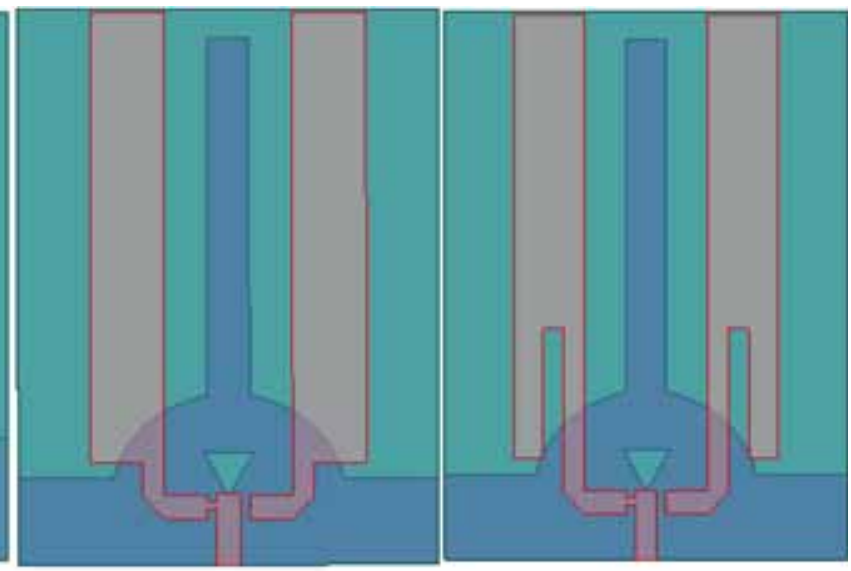

(b) Antenna 2 (c) Antenna 3
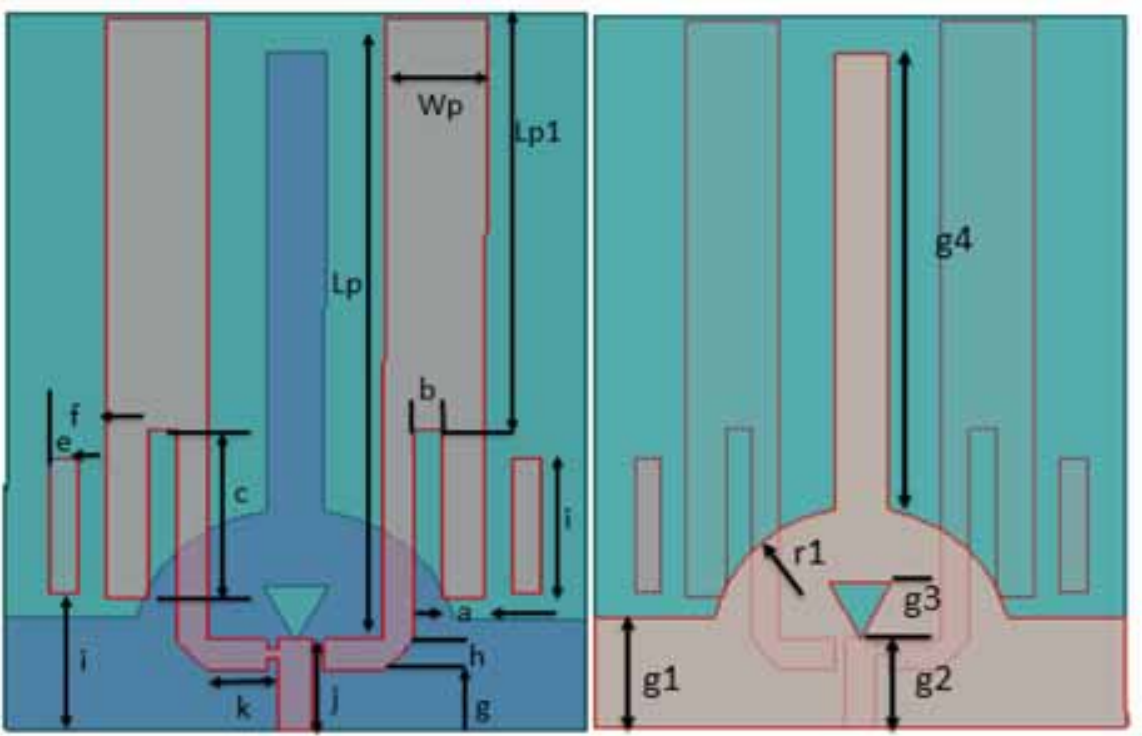

(d) Proposed antenna front and back view

Figure 1. Design evolution of the proposed antenna. 


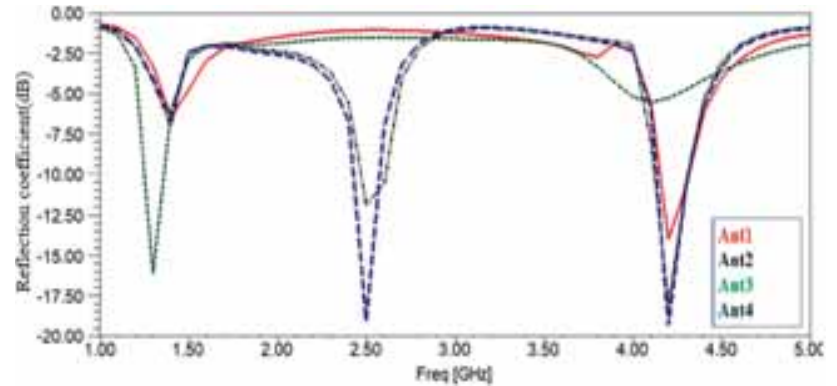

Figure 2. Simulated $S_{11}$ of antenna iterations.

operating in the lower frequencies form $1.25 \mathrm{GHz}$ to $1.35 \mathrm{GHz}$ with $0.1 \mathrm{GHz}$ bandwidth and return loss $-16 \mathrm{~dB}$. In the design 3 the antenna is modified with rectangular slots at the two symmetrical radiators. The S11 of the antenna 3 resonates at two frequencies of $2.5 \mathrm{GHz}$ and $4.2 \mathrm{GHz}$. In the proposed antenna design the two-parallel rectangular parasitic elements are loaded. The

\section{E-plane}
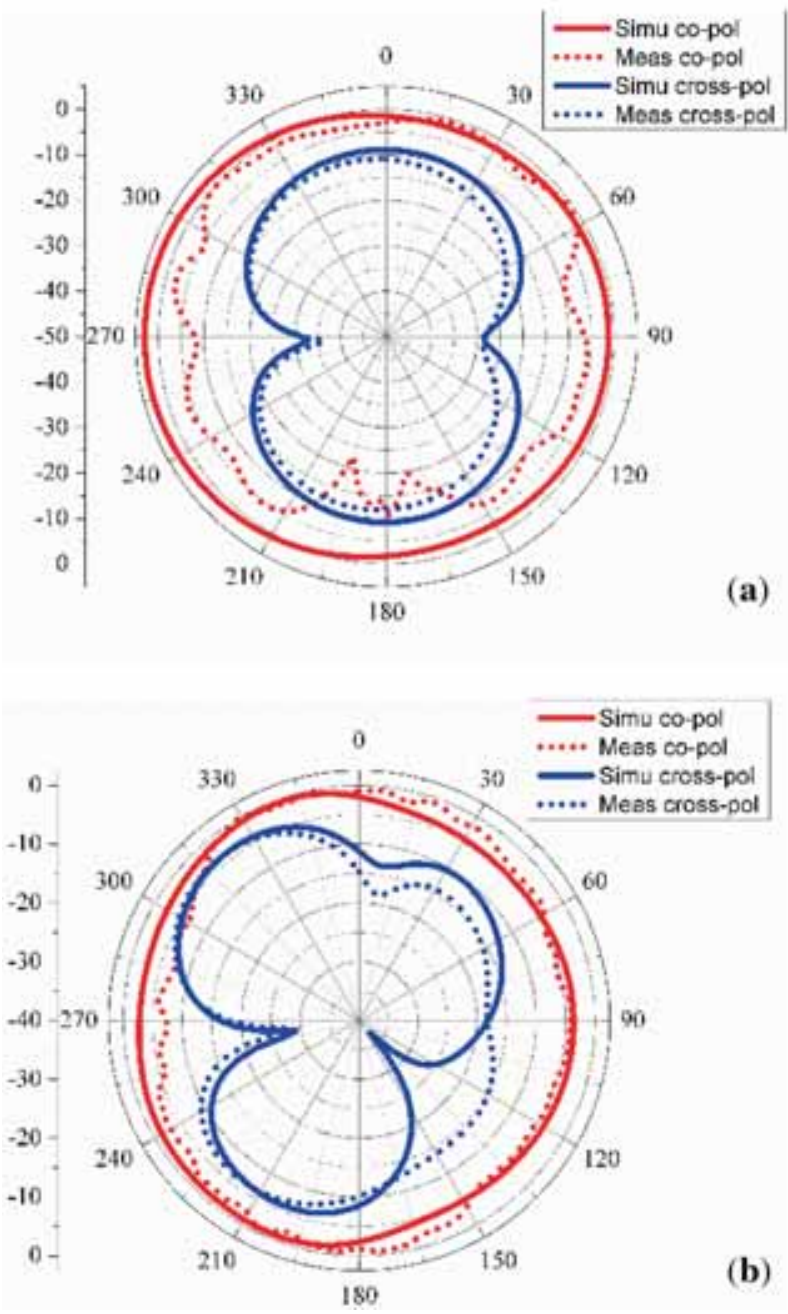

results of the antenna 3 and the proposed antenna is similar to each other, but the return loss of the proposed antenna reaches $-19 \mathrm{~dB}$ at the two resonating frequencies. The proposed antenna resonating at $2.5 \mathrm{GHz}$ and $4.2 \mathrm{GHz}$ with FR4 substrate material and when the antenna is placed on the polyimide substrate, the antenna resonating at $2.45 \mathrm{GHz}$ and $4.25 \mathrm{GHz}$.

The radiation pattern of the proposed antenna (Antenna 4) which is operating at $2.5 \mathrm{GHz}$ and $4.2 \mathrm{GHz}$ with copolarization and cross-polarization patterns (E-plane and $\mathrm{H}$-plane) are given in figure 3. In the E-plane the co-polarization radiation is distributed in the omni-directional pattern and the cross-polarization radiation patterns are in the bidirectional pattern. For the higher frequency, the radiation pattern is distributed in Omni-directional and semi-bidirectional at $\mathrm{E}$ and $\mathrm{H}$ planes, respectively. The surface current distribution on the surface the radiating at the two-resonating frequencies is observed in figure 4 the minimal amplitude of current distribution occurs at the end of the symmetrical radiators and maximal amplitude occurs

\section{H-plane}
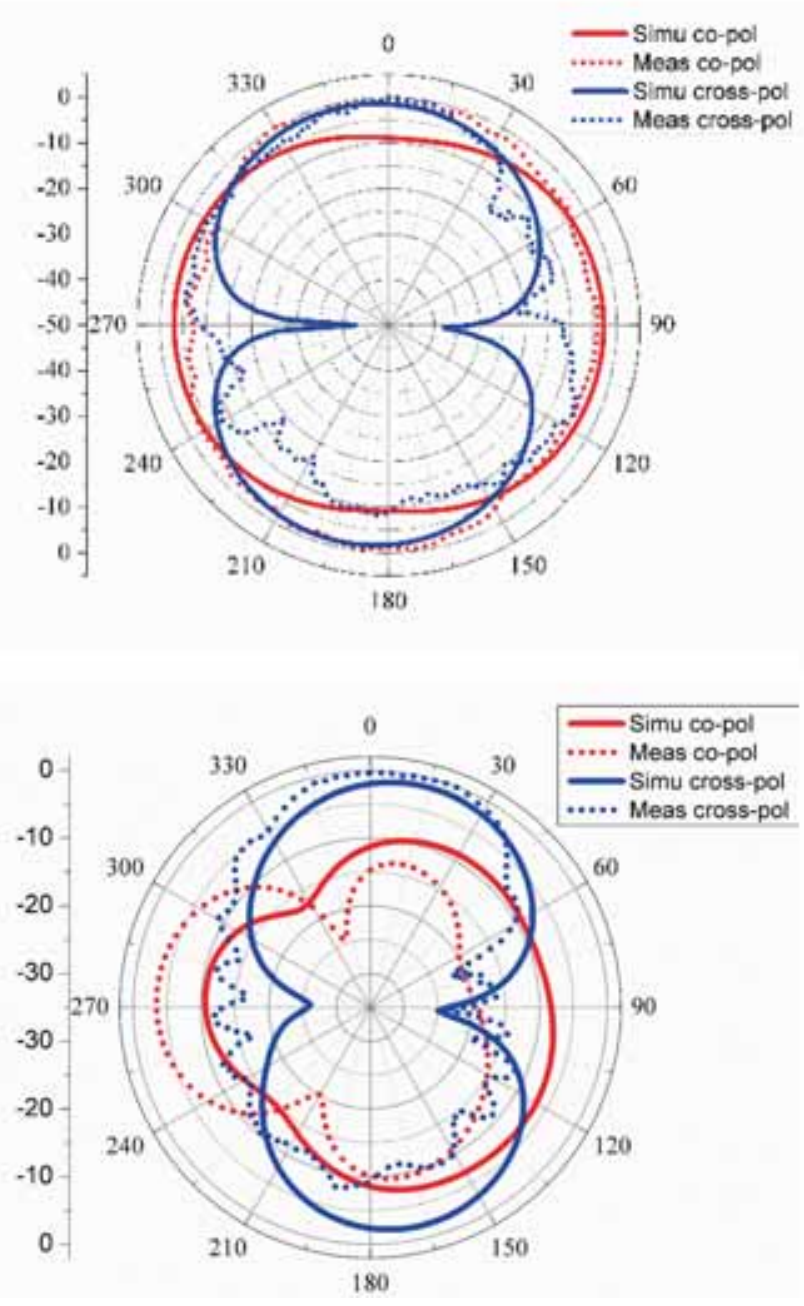

Figure 3. Radiation patterns of at different frequencies (a) $2.5 \mathrm{GHz}$, (b) $4.2 \mathrm{GHz}$. 

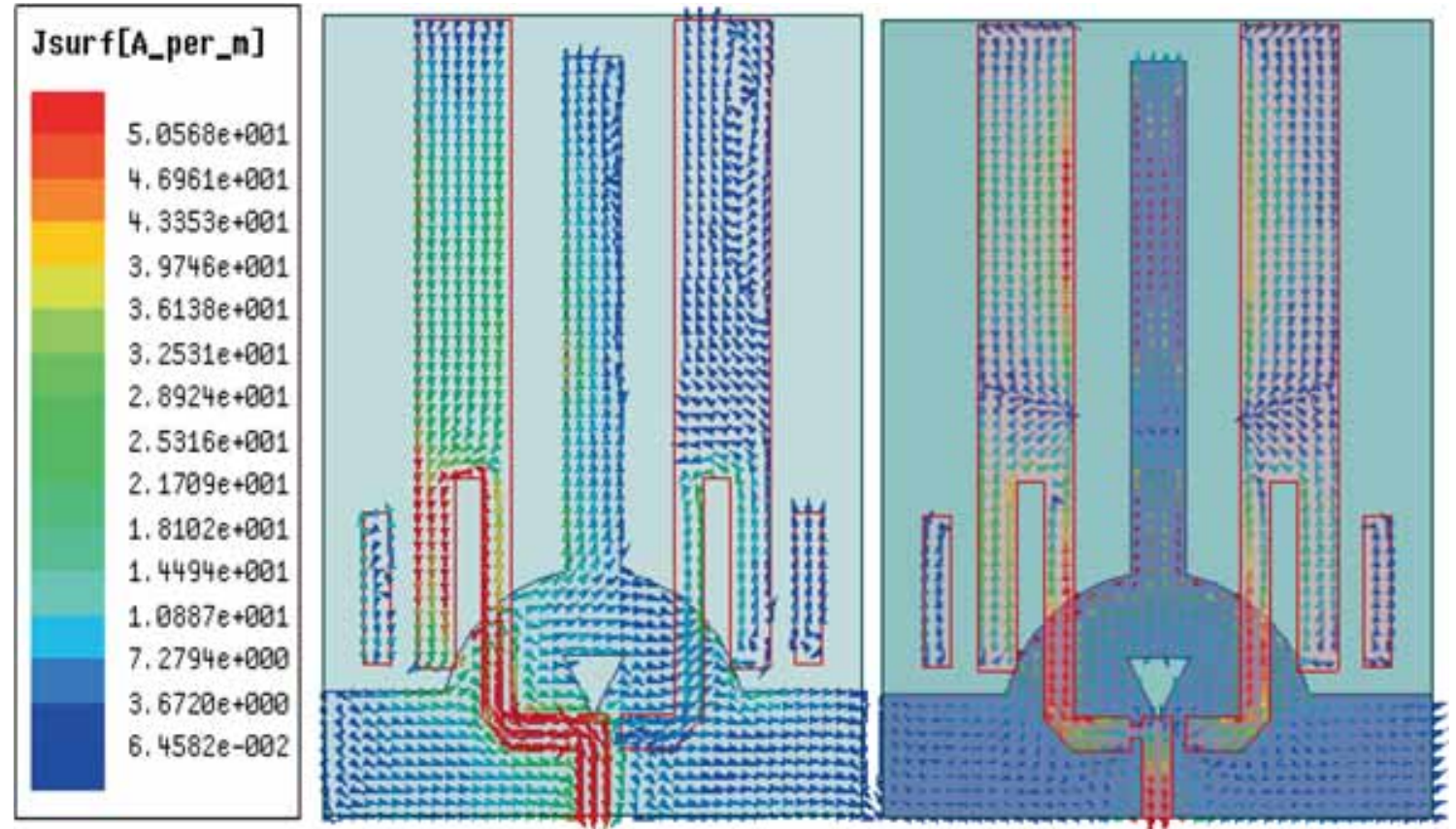

Figure 4. Surface current distribution at (a) $2.5 \mathrm{GHz}$, (b) $4.2 \mathrm{GHz}$.

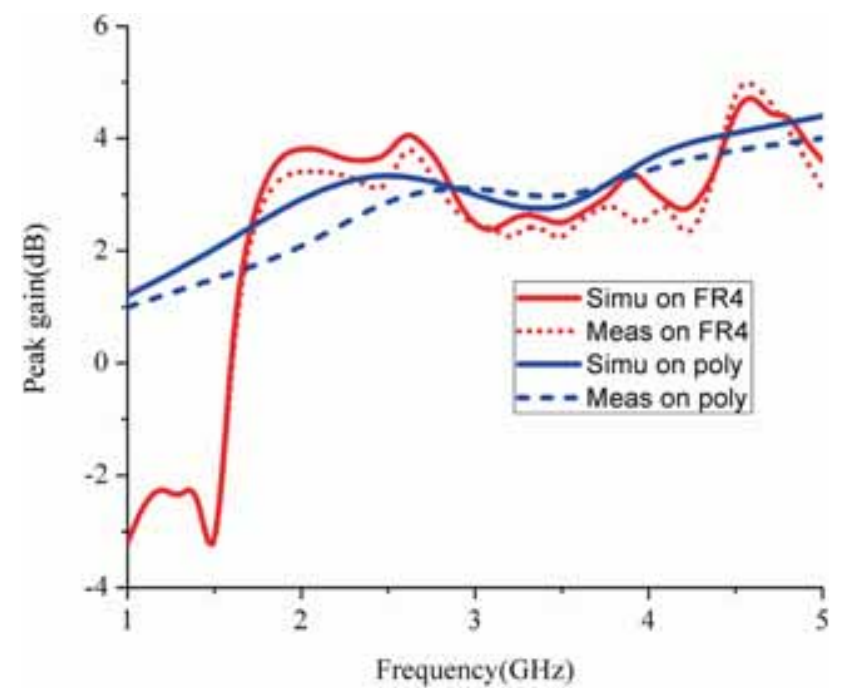

Figure 5. Peak gain of the proposed antenna.

at the feeding and the starting edges of the symmetrical radiators.

Figure 5 represents the simulated and measured gain of the antenna with respect to the operating frequency. The observed simulated peak gain is of $3.5 \mathrm{~dB}$ at $2.5 \mathrm{GHz}$ and $5.5 \mathrm{~dB}$ at $4.2 \mathrm{GHz}$ and the measured peak gain of $3.2 \mathrm{~dB}$ at $2.5 \mathrm{GHz}$ and $5.2 \mathrm{~dB}$ at $4.2 \mathrm{GHz}$, respectively for FR4 substrate. Similarly, when the antenna is placed on the polyimide substrate the observed gain values of $3.2 \mathrm{~dB}$ at $2.45 \mathrm{GHz}$ and $3.9 \mathrm{~dB}$ at $4.25 \mathrm{GHz}$ for the simulation and
$2.8 \mathrm{~dB}$ at $2.45 \mathrm{GHz}$ and $3.6 \mathrm{~dB}$ at $4.25 \mathrm{GHz}$ is observed for measured results.

\subsection{On body placement}

A three-layer human phantom is designed with rectangular boxes shown in figure 6 . The model consists of the skin, fat and muscle layers [23, 24]. The different characteristics of the human tissues such as relative permittivity and conductivity are considered for designing the human phantom. Antenna is placed in the depth of $2 \mathrm{~mm}$ inside the skin tissue. When the antenna placed under the skin, the radiation is the off-body direction and has negative peak gain. The negative gain is because of the dissipation caused around the human tissue. To place the antenna in the real time, the antenna should be wrapped by the biocompatible materials to avoid the shorting. Bending of the antenna according to the skin tissue is one of the critical design aspects. Depending on the bending sensitivity, the antenna performance can be studied. Regarding the safety issues, the SAR values are evaluated at the centre frequency $2.5 \mathrm{GHz}$. If the input power is set to $1 \mathrm{w}$ the averaged SAR values are over $1 \mathrm{~g}$ of tissue should be less than $1.6 \mathrm{~W} / \mathrm{kg}$. So, for the designed antenna the averaged SAR values are $79 \mathrm{~W} / \mathrm{kg}$ at $2.5 \mathrm{GHz}$. This is higher than the standards, so to maintain the standards the input signal should be decreased to $300 \mathrm{mw}$ to meet the regulations (table 1).

For studying the simulation results, two main conditions are considered. One aspect is implantable antenna inside the body and other is external to the body. For simulation of 

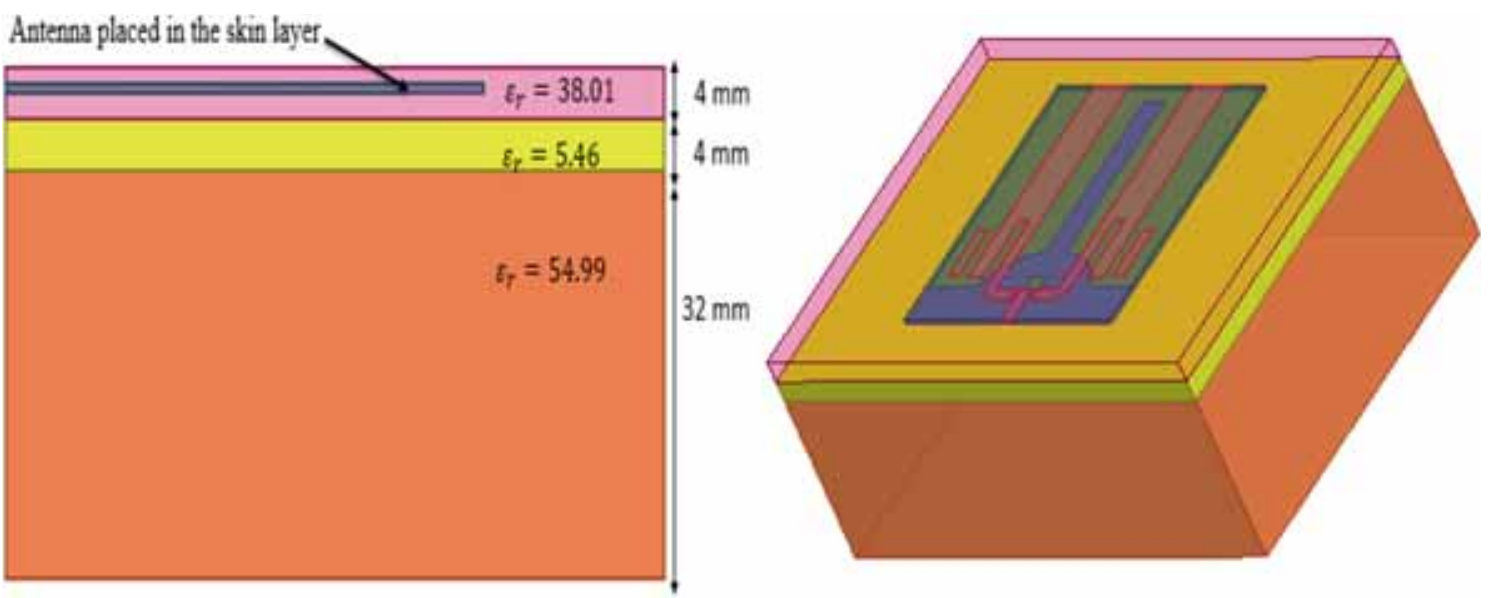

Figure 6. Three layered phantom layer model.

Table 1. Design parameters of antenna.

\begin{tabular}{lccc}
\hline Parameter & Value $(\mathrm{mm})$ & Parameter & Value $(\mathrm{mm})$ \\
\hline Lp & 50.3 & $\mathrm{Wp}$ & 7.0 \\
Lp1 & 33.3 & $\mathrm{a}$ & 2.9 \\
b & 2 & $\mathrm{c}$ & 13.7 \\
$\mathrm{f}$ & 3.9 & $\mathrm{~g}$ & 4.7 \\
$\mathrm{~h}$ & 2.5 & $\mathrm{i}$ & 11.6 \\
j & 7.3 & $\mathrm{k}$ & 5.0 \\
g1 & 9.0 & $\mathrm{~g} 2$ & 7.2 \\
g3 & 4.5 & $\mathrm{e}$ & 2.0 \\
g4 & 37.3 & $\mathrm{~h}$ & 0.8 \\
Ls & 58 & $\mathrm{Ws}$ & 40 \\
\hline
\end{tabular}

Table 2. Phantom permittivity and conductivity.

\begin{tabular}{lcc}
\hline Tissue & Relative permittivity & Conductivity $(\mathrm{S} / \mathrm{m})$ \\
\hline Skin & 38.01 & 1.46 \\
Fat & 5.46 & 0.10 \\
Muscle & 54.99 & 1.74 \\
\hline
\end{tabular}

the implantable antenna relative permittivity and the conductivity of the human phantom is considered as shown in table 2. When the antenna is inside the skin tissue it will have two main effects. One is decrement in the resonant antenna frequency because of the high dielectric constant of human tissues and the second one is reduction of the gain due to high conductivity in the human tissues. Figure 6 shows the representation of the three-layer tissue model with their dielectric constants. The antenna model is placed in the three-layered phantom model with depth of $2 \mathrm{~mm}$ under the skin. The antenna resonating at single frequency band and covers the frequency range from $2.15 \mathrm{GHz}$ to $2.8 \mathrm{GHz}$ with bandwidth of $0.65 \mathrm{GHz}$. At the centre frequency of $2.5 \mathrm{GHz}$ (ISM Band) antenna showing the minimum reflection coefficient of $-35 \mathrm{~dB}$.

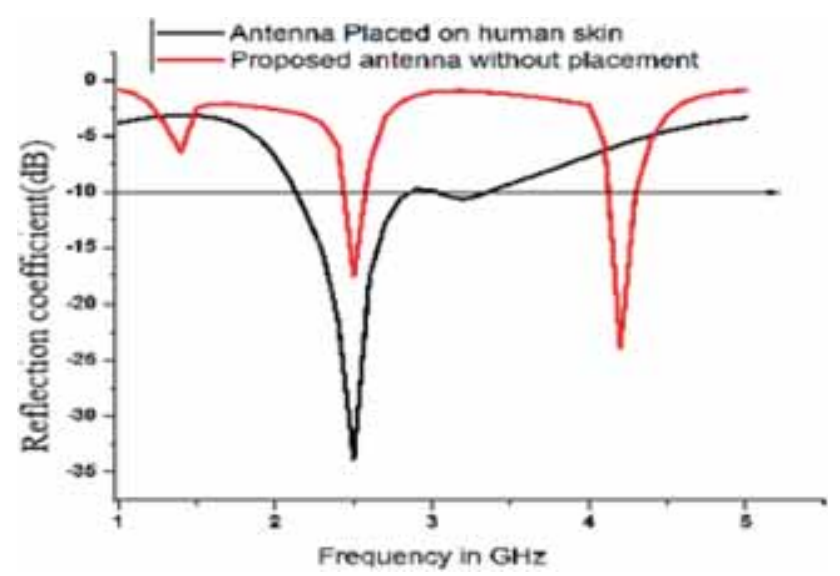

Figure 7. Simulated $\mathrm{S}_{11}$ of Proposed antenna and antenna placed in the skin tissue.

The simulated reflection coefficient of the proposed antenna and the antenna placed in the skin are presented in figure 7.

As per the set international guidelines, maximum allowable SAR to preserve the human safety over $10 \mathrm{~g}$ contiguous tissue is less than $2 \mathrm{~W} / \mathrm{kg}$. The guidelines given by the IEEE C95-1-2005 standards says the $10 \mathrm{~g}$ of the tissue in the shape of cube should be less than $2 \mathrm{~W} / \mathrm{kg}$. Net input power set to the antenna is $1 \mathrm{w}$. Because of the negative effects of the electromagnetic emission effects so SAR study is given the more importance in this paper. For calculating the SAR, the formula is given by

$$
S A R=\int \frac{\sigma(r)|E(r)|^{2}}{\rho(r)} d r
$$

where $\sigma$ electric conductivity of the sample $\rho$ is the sample density, $\mathrm{E}$ is the RMS electric field of the sample.

In designing of these kinds of implantable or wearable antennas back radiation is taken as one of the major 
considerations. Before calculating the SAR values, the reference power of the antenna is set $300 \mathrm{mw}$. In default the reference power is taken as $1 \mathrm{w}$, higher input power gives

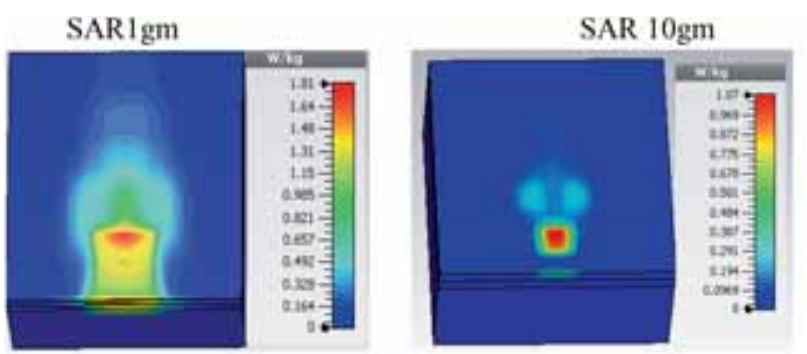

(a) SAR distribution when the antenna is placed $2 \mathrm{~mm}$ inside the skin at $2.5 \mathrm{GHz}$.

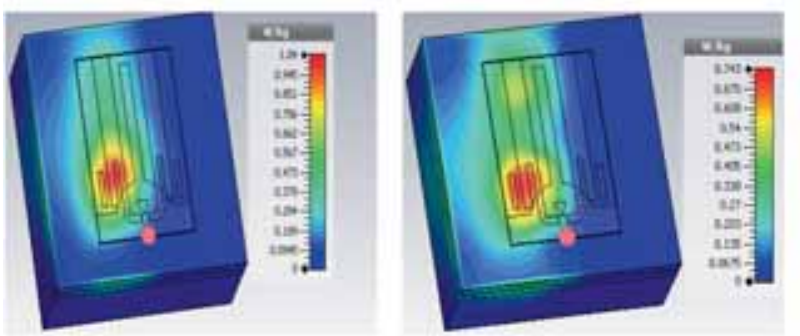

(b) SAR distribution when the antenna is placed $0 \mathrm{~mm}$ from the skin at $2.5 \mathrm{GHz}$.

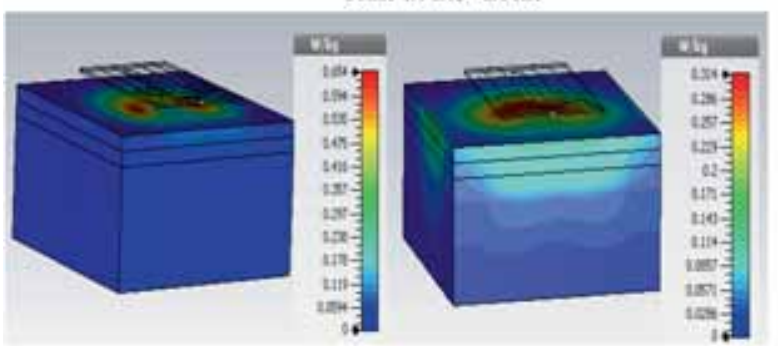

(c) SAR distribution when the antenna is placed $5 \mathrm{~mm}$ outside the skin at $2.5 \mathrm{GHz}$
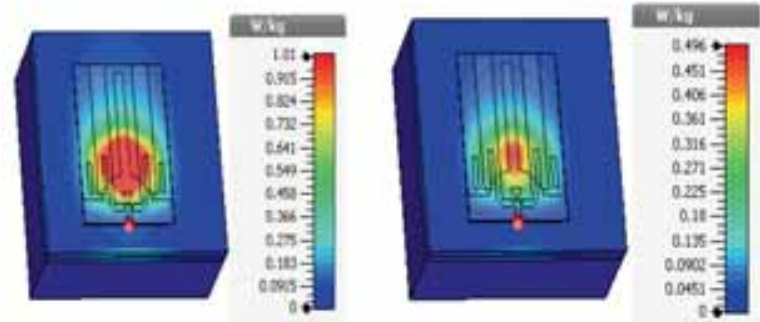

(d) SAR distribution when the antenna is placed $0 \mathrm{~mm}$ outside the skin at $4.2 \mathrm{GHz}$.

Figure 8. SAR distribution on the three-layered phantom model. rise to higher SAR values. So, to maintain the standards we need to adjust the reference power values. The SAR calculation are carried out in the commercial software CST 2014 [25]. In three-layer phantom model has three different relative permittivity's and conductivities noted in table 2 the SAR values mainly depends on the two aspects one is distance between the human model and skin layer and the frequency of operation of the antenna. In recent advances many of the approaches like ECG/AMC (artificial magnetic conductor's) surfaces are used to reduce the SAR values. Most of the SAR values are influenced by the type of the radiation pattern, antenna position and type of the antenna used in the design. Recent studies in electro band gap structures reduce the surface wave and prevent the undesired radiation from the ground structure. The SAR values depend on the operating frequency of the antenna. When the frequency of the antenna is increased, the SAR values are going to be reduced to some extent. For the higher frequencies the energy absorption occurs primarily on the body surface and the penetration of EMF (Electromagnetic fields) in to skin is very short for which the observed values are less when compared with lower frequencies.

The SAR is calculated for the antenna placed inside the skin tissue with $2 \mathrm{~mm}$ depth. Figure 8 shows the radiation spread in the skin tissue with SAR value of $1.81 \mathrm{~W} / \mathrm{kg}$ at the resonant frequency of $2.5 \mathrm{GHz}$. SAR is calculated for different heights from the three-layer phantom model and different tissues like fat and muscle and the SAR values are noted in table 3. The parametric analysis of the SAR is calculated on skin for another resonating frequency like 4.2 GHz. The SAR values are calculated on the $1 \mathrm{~g}$ and $10 \mathrm{~g}$ of tissue. The observed values of $1.01 \mathrm{~W} / \mathrm{kg}$ and $0.469 \mathrm{~W} / \mathrm{kg}$ are observed. When compared with the $2.5 \mathrm{GHz}$, the observed SAR values are less.

To understand some of the critical parameters of the design, the parametric study is done. The optimized parameters of the radiating conductors and ground plane are

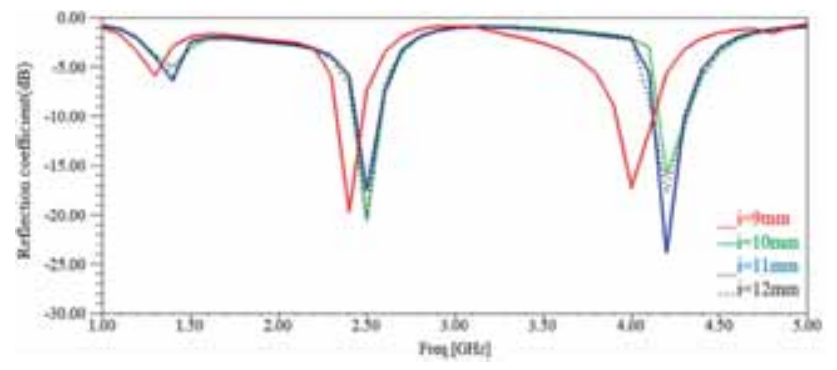

Figure 9. Parametric analysis for length of the parasitic element is varied.

Table 3. SAR values for the antenna placed in different heights.

\begin{tabular}{|c|c|c|c|c|c|c|}
\hline \multirow{2}{*}{$\frac{\text { Resonance frequency }}{2.5 \mathrm{GHz}}$} & \multicolumn{2}{|c|}{$2 \mathrm{~mm}$ inside phantom } & \multicolumn{2}{|c|}{ On body } & \multicolumn{2}{|c|}{$5 \mathrm{~mm}$ outside phantom } \\
\hline & $\begin{array}{c}1 \mathrm{~g} \\
1.81 \mathrm{~W} / \mathrm{kg}\end{array}$ & $\begin{array}{c}10 \mathrm{~g} \\
1.07 \mathrm{~W} / \mathrm{kg}\end{array}$ & $\begin{array}{c}1 \mathrm{~g} \\
1.04 \mathrm{~W} / \mathrm{kg}\end{array}$ & $\begin{array}{c}10 \mathrm{~g} \\
0.73 \mathrm{~W} / \mathrm{kg}\end{array}$ & $\begin{array}{c}1 \mathrm{~g} \\
0.31 \mathrm{~W} / \mathrm{kg}\end{array}$ & $\begin{array}{c}10 \mathrm{~g} \\
0.65 \mathrm{~W} / \mathrm{kg}\end{array}$ \\
\hline
\end{tabular}




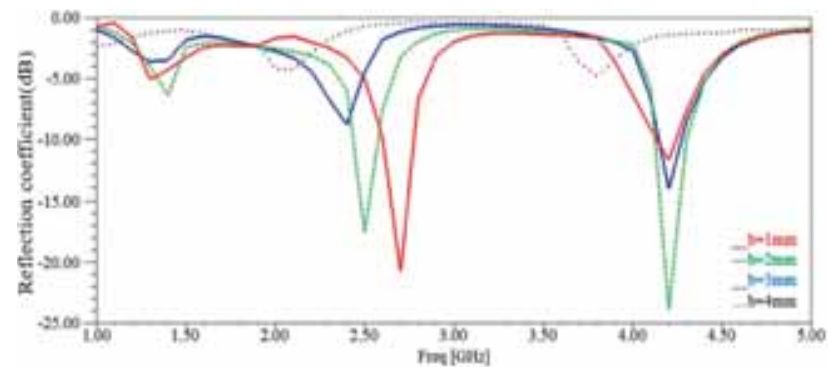

Figure 10. Parametric analysis for length of the rectangular ground is varied.

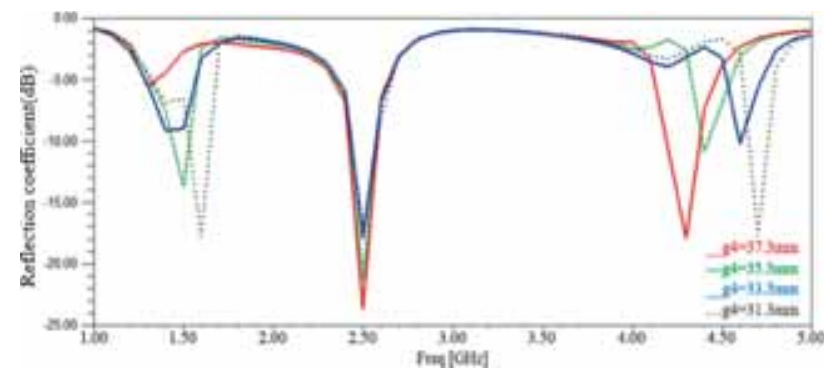

Figure 11. Parametric analysis for length of the rectangular ground is varied.

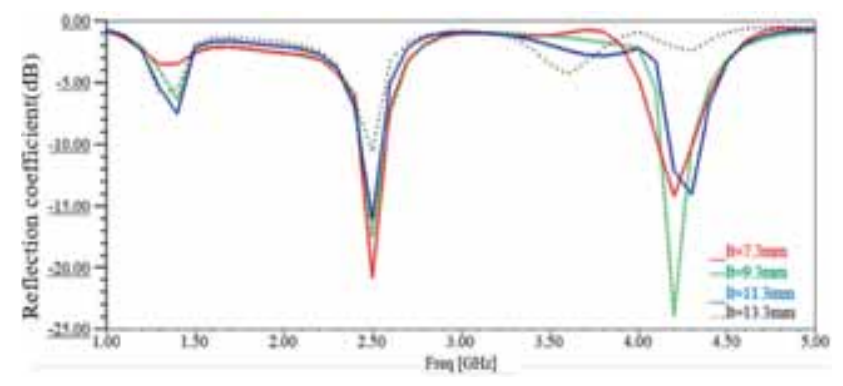

Figure 12. Parametric analysis for length of the feed is varied. shown in figure 9. The return loss variation can be studied by changing the length of the radiating parasitic element on the patch. By varying the ' $\mathrm{I}$ ' value from $9 \mathrm{~mm}$ to $12 \mathrm{~mm}$ is studied and antenna shows the dual band nature. By observing the plot, we can see when $\mathrm{I}=9 \mathrm{~mm}$ there is a shift in the frequency and resonates at $2.4 \mathrm{GHz}$ and $3.8 \mathrm{GHz}$. The width of the slot ' $b$ ' is varied from $1 \mathrm{~mm}$ to $4 \mathrm{~mm}$ to obtain the desired value of the parametric analysis. When the width of the slot is $1 \mathrm{~mm}$, the antenna operating in the frequency of $2.6 \mathrm{GHz}$. When the slot width is increased, we observed left shift in the frequency. When the width of the slot is $4 \mathrm{~mm}$, the antenna did not show any reflection coefficient. For the second resonating frequency band, there is a slight variation of S11 observed at $4.2 \mathrm{GHz}$. The parameters like rectangular length of the stub loaded in ground and the length of the feed are varied to get the optimized values. A minor change in the any of the parameters has a significant effect in the impedance matching, resonating frequency, bandwidth for the operating frequencies and depth of S11. During the parametric analysis, other than the varying parameter all other values are kept constant (figures 10, 11, 12).

A comparison between the proposed antenna and the literature available are presented in table 3 . The proposed model is providing low SAR compared with other most of the models proposed by the earlier researchers. The impedance bandwidth also considerably high and gain is also negative when antenna placed in the real-time environment.

Antenna is prototyped, and those images are presented in figure 13. Microstrip line feeding is used with $50 \mathrm{ohm}$ impedance at the feed point. The measured results of S11 and VSWR of the antenna is presented in figure 14. In the reflection coefficient, dual band characteristics can be observed with value $<-10 \mathrm{~dB}$ on both the FR4 substrate and on the polyimide substrate with Anritsu combinational analyzer.

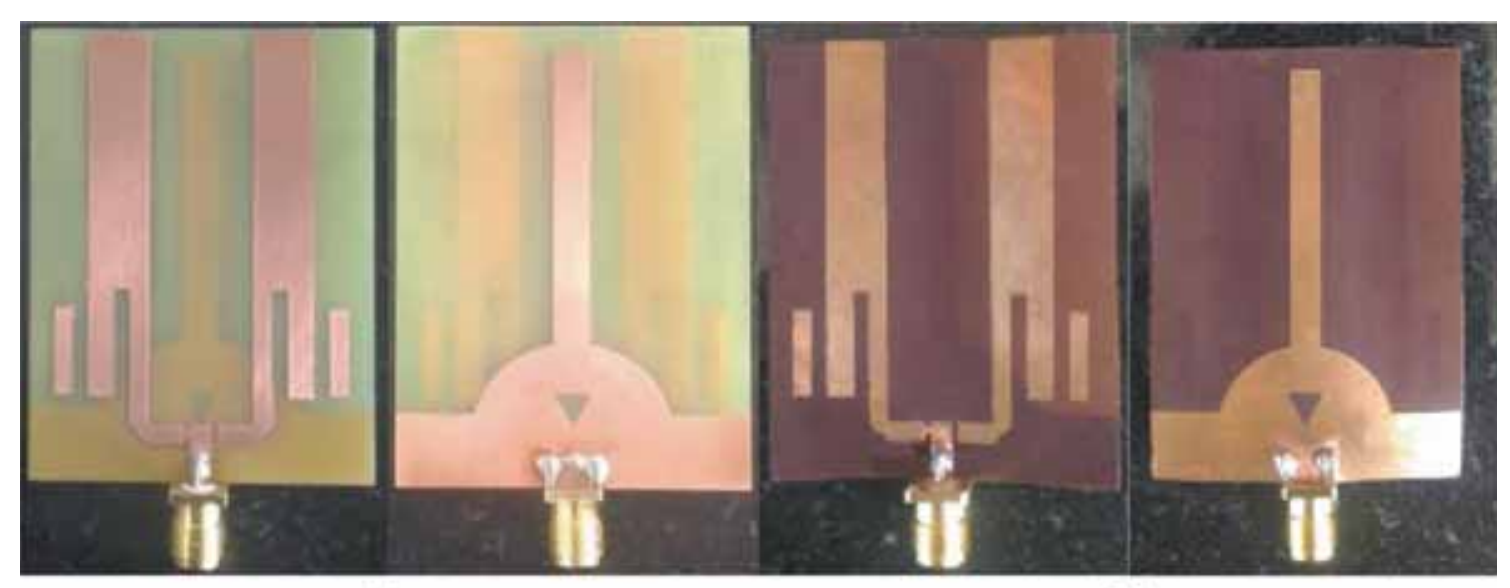

(a)

(b)

Figure 13. Prototyped Antenna Model Front and back view on (a) FR4 substrate, (b) polyimide substrate. 
The proposed antenna performance is evaluated in the phantom liquid and animal tissue [26]. The photos of the experimental set-up are shown in figure 15. The measured frequencies are operating at dual band of $2.5 \mathrm{GHz}$ and 4.2 GHz. There is a minor discrepancy between the simulation and measured results. To create the human phantom fluids deionized water, Nacl and sugar are used. In the created biomedical environment, the antenna is immersed in to glass baker filled with liquid medium and tested. Similarly, the antenna is placed in the animal tissue and verified. The results support the applicability of the antenna model in real-time environment. To do the measurement set-up the meat muscle is considered to

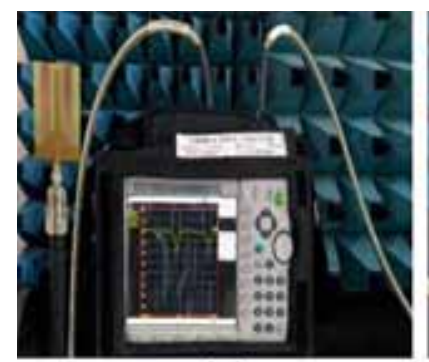

(a)

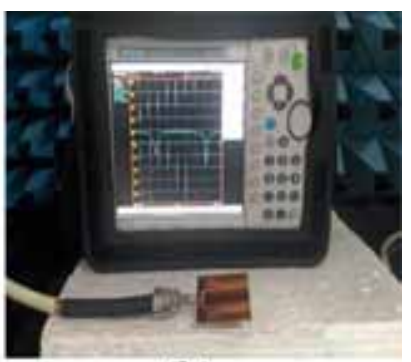

(b)
Figure 14. Measurement results of $S_{11}$ on (a) FR4 substrate, (b) polyimide substrate.
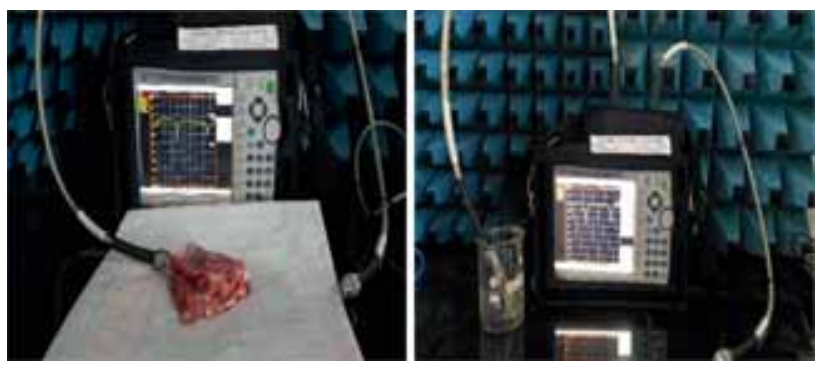

Figure 15. Real-time measurement with antenna in animal tissue and deionized water.

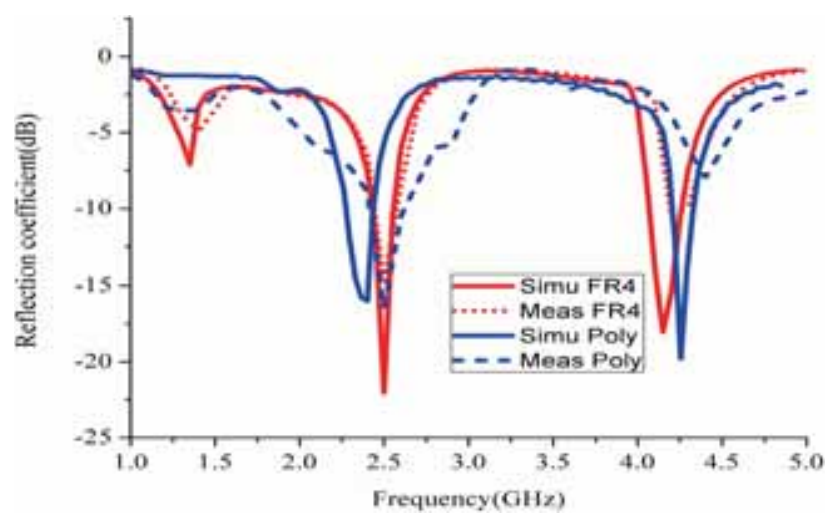

Figure 16. Simulated and measured results of the proposed antennas using FR4 and polyimide substrates.
Table 4. Comparison of the proposed antenna with literature.

\begin{tabular}{lclc}
\hline References & $\begin{array}{c}\text { BW/fc } \\
(\%)\end{array}$ & $\begin{array}{c}\text { Gain } \\
(\mathrm{dBi})\end{array}$ & $\begin{array}{c}\text { SAR } \\
(\mathrm{W} / \mathrm{kg})\end{array}$ \\
\hline Xu et al (2013) [18] & 28.3 & -28 & 484 \\
Liu et al (2009) [19] & 30 & -38 & 903 \\
Chein et al (2010) [20] & 33.5 & -24 & 797 \\
Li et al (2014) [21] & 22.8 & -30.5 & 609.2 \\
Sofia and Koulouridis & 26 & -29.4 & 476.5 \\
$\quad$ (2015) [5] & & & \\
Cho and Yoo (2016) [22] & 8.6 & -21.2 & 491 \\
Proposed antenna & 30 & -26.2 & 479 \\
\hline
\end{tabular}

create the biomedical environment. The dielectric constant of the meat is measured using the Agilent $85070 \mathrm{E}$ dielectric probe and found 51.9. When compared to simulation, a small dissimilarity was observed in the reflection coefficient.

The comparison of the simulated and measured results is presented in figure 16. When the antenna is placed on the FR4 substrate, the reflection coefficient measured are like simulation results. When the antenna is placed on the polyimide substrate the measured results are slightly shifted and the second resonating frequency is shifted to $4.25 \mathrm{GHz}$ and comparison of previous literature is done in table 4 .

\section{Conclusion}

The analysis of an implantable antenna for biomedical applications is presented. The proposed antenna operates from 2.15 to $2.8 \mathrm{GHz}$, which covers ISM band. The peak gain of the antenna $3.5 \mathrm{~dB}$ at $2.5 \mathrm{GHz}$ and when the antenna is placed in the three-layered phantom, it produced the negative gain. The radiation patterns obtained are Omni directional patterns in H-plane and bidirectional like pattern in E-Plane. The antenna placed in the phantom layer satisfies the SAR standards provided by IEEE C95.1:2005 and ICNIRP. SAR calculation is carried out to measure radiation effects of those antennas in the human body. The antenna is placed inside the skin phantom and outside to get the variation in SAR values. As the distance between the antenna and phantom increases, we observed lower SAR values. The proposed antenna with the obtained results is suitable for ISM band health condition monitoring systems.

\section{Acknowledgements}

The authors express their gratitude to ALRC Research Centre, Department of ECE, K L University and Department of Science and Technology (DST) for the Grant ECR/ 2016/000569, and EEQ /2016/000604. 


\section{References}

[1] Masood, Rizwan, Christian Person and Ronan Sauleau 2017 A dual-mode, dual-port pattern diversity antenna for 2.45GHz WBAN. IEEE Antennas and Wireless Propag. Lett. 16: 1064-1067

[2] Shakib, Mohammed Nazmus, Mahmoud Moghavvemi and Wan Nor Liza Binti Wan Mahadi 2017 Design of a tri-band off-body antenna for WBAN communication. IEEE Antennas and Wireless Propagation Lett. 16: 210-213

[3] Tak, Jinpil, Woo S, Kwon J and Choi J 2016 Dual-band dualmode patch antenna for on-/off-body WBAN communications. IEEE Antennas and Wireless Propag Lett. 15: 348-351

[4] Sakthi, Abhaikumar, Nair RS and Raju 2016 Design and equivalent circuit analysis of textile antenna for WLAN and WBAN application. In: Region 10 Conference (TENCON)

[5] Bakogianni, Sofia and Stavros Koulouridis 2016 An implantable planar dipole antenna for wireless medradioband biotelemetry devices. IEEE Antennas and Wireless Propag Lett. 15: 234-237

[6] Kim, Jaehoon and Yahya Rahmat-Samii 2004 Implanted antennas inside a human body: simulations, designs, and characterizations. IEEE Trans. Microwave Theory and Techniques 2: 1934-1943

[7] Steinhaus B M, Smith R E and Crosby P 1994 The role of telecommunications in future implantable device systems engineering in medicine and biology society. In: proceedings of the 16th annual international conference of the IEEE engineering advances: new opportunities for biomedical Engineers, vol. 2

[8] Bahrami H, Mirbozorgi S A, Ameli R, Rusch L A and Gosselin B 2016 Flexible, polarization-diverse UWB antennas for implantable neural recording systems. IEEE Trans. Biomedical Circuits and Systems 10: 38-48

[9] Ahlbom A 1998 Guidelines for limiting exposure to timevarying electric, magnetic, and electromagnetic fields (up to 300 GHz). Health Physics 74: 494-521

[10] Xu, Li-Jie, Yong-Xin Guo and Wen Wu 2012 Dual-band implantable antenna with open-end slots on ground. IEEE Antennas and Wireless Propag Lett. 11: 1564-1567

[11] Xu Li-Jie 2016 A dual-band on-body repeater antenna for body sensor. Network IEEE Antennas and Wireless Propag Lett. 15: 1649-1652

[12] Gemio, Joan, Josep Parron and Soler J 2010 Human body effects on implantable antennas for ISM bands applications: Models comparison and propagation losses study. Progress in Electromagnetics Research 10: 437-452

[13] Lee, C-M (2008) Dual-resonant $\pi$-shape with double L-strips PIFA for implantable biotelemetry. Electronics Lett. 44: 837-839
[14] Khan Habibulla, Madhav B T, Lakshmi B Sree, Sowmya Lakshmi, Veena P and Prasanth N S 2015 Analytical study of specific absorption rate distribution on different antennas operating at $2.4 \mathrm{GHz}$ using HFSS. Int. J. Appl. Eng. 10(8): 198-198

[15] Felício J M, Fernandes C A and Costa J R 2016 Wideband implantable antenna for body-area high data rate impulse radio communication. IEEE Trans. Antennas and Propag. 64: $1932-1940$

[16] Tsai, Chi-Lin, Kuan-Wei Chen and Chin-Lung Yang 2014 Implantable wideband low-SAR antenna with C-shaped coupled ground. IEEE Antennas and Wireless Propag. Lett. 14: $1594-1597$

[17] Kaschel, Hector and Cristian Ahumada 2016 Design of a triband antenna microstrip for a WBAN the low SAR Automatica (ICA-ACCA). IEEE Int. Conference on IEEE

[18] Xu L J, Guo X, Wu W 2013 Miniaturised slot antenna for biomedical applications. Electron. Lett 49: 1060-1061

[19] Liu W C, Chen S H and Wu C M 2009 Bandwidth enhancement and size reduction of implantable PIFA antenna for biotelemetry devices. Microwave Opt. Techno Lett. 51(3): 755-757

[20] Chien T F, Cheng C M, Yang H C, Jiang J W and Luo C H 2010 Development of nonsuperstrate implantable low-profile CPW-fed ceramic antennas. IEEE Antennas Wireless Propag. Lett. 9: 599-602

[21] Liu C, Cheng C M, Guo Y X and Xiao S 2012 A hybrid patch/slot implantable antenna for biotelemetry devices. IEEE Antennas Wireless Propag. Lett. 11: 1646-1649

[22] Cho Y and Yoo H 2016 Miniaturised dual-band implantable antenna for wireless biotelemetry. Electronics Lett. 52(12): 1005-1007

[23] Liu X Y, Wu Z T, Fan Y and Tentzeris E M 2017 A miniaturized CSRR loaded wide-beamwidth circularly polarized implantable antenna for subcutaneous real-time glucose monitoring. IEEE Antennas and Wireless Propag. Lett. 16: 77-580

[24] Duan Z, Guo Y X, Je M and Kwong, D L 2014 Design and in vitro test of a differentially fed dual-band implantable antenna operating at MICS and ISM bands. IEEE Transactions on Antennas and Propag. 62(5): 2430-2439

[25] Hoque A K M F, Hossain M S, Mollah A S and Akramuzzaman, M 2013 A study on specific absorption rate (SAR) due to nonionizing radiation from wireless/ telecommunication in Bangladesh. Am. J. Phys. 1(3):104-110

[26] Tsai C L, Chen K W and Yang C L 2017 Implantable wideband low-specific-absorption-rate antenna on a thin flexible substrate. IEEE Antennas and Wireless Propag Lett. 15: 1048-1052 